Original Article

\title{
An injury risk model for large construction projects
}

\author{
Søren Spangenberg \\ National Research Centre for the Working Environment, Lersø Parkallé 105, \\ DK-2100, Copenhagen, Denmark. \\ E-mail:ssp@nrcwe.dk
}

\begin{abstract}
A risk management model for prevention of occupational injuries at large construction projects is presented. The model combines the engineering CDIO-phase model (conceive, design, implement or construct, operate) with a socio-cultural approach to safety management. The risk management model is targeting clients/owners of the projects. In this study the model is used for categorization of existing injury prevention measures (personal, structural or cultural change) at large construction projects in Denmark, and for evaluation of the effect. The majority of the injury prevention measures were implemented during the construction phase and belonged to the category structural change (for example, safety walk-rounds and safety audits). The study showed that injury prevention may be improved at future projects by implementing more measures influencing norms and culture at the construction site (for example, the pioneer client concept), and thus increase the diversity of injury prevention measures. Many injury incidents originate from the design phase. Future safety research should focus more on developing injury prevention measures for this phase.
\end{abstract}

Risk Management (2009) 11, 111-134. doi:10.1057/rm.2009.5

Keywords: injury risk factors; injury risk model; injury prevention measures; CDIO-phases; construction industry

\section{Introduction}

\section{Setting the stage}

The construction industry continues to be one of the most hazardous industries in terms of serious injuries, lost working time (Dong et al, 1995; Brenner and Ahern, 2000; Derr et al, 2001), hospitalization (Spangenberg et al, 2005a), disability (Hannerz et al, 2005) and mortality (Tüchsen et $a l, 2005)$ and there is a great need to improve occupational safety and 
health of the employees. In general, there are three main areas in the construction industry: building construction, rail and road construction, and industrial construction. This paper deals with injury prevention and large construction projects. The emphasis is on major transportation infrastructure projects, but the conclusions also apply to a wide range of other project types, for example hospitals, power plants, dams, and oil and gas offshore projects.

The trans-European transport networks are under continuous development such as with the Channel Tunnel between England and France and the high-speed railway systems in central Europe (The Trans-European Transport Networks' homepage). The legal basis for the transport networks is provided in the Treaty on the European Union. Under the terms of Chapter XV of the Treaty (Articles 154, 155 and 156), the European Union must aim to promote the development of trans-European networks as a key element for the creation of the internal market and the reinforcement of economic and social cohesion. This development includes the interconnection and interoperability of national networks as well as access to such networks. The financial resources needed to complete the network are estimated to be several hundred billion euros. The Danish construction industry has been involved in the completion of three large and complex bridge and tunnel traffic links. The Great Belt link reaches across the Great Belt, connecting east and west Denmark, while the Øresund link provides a fixed link between Denmark and Sweden, and the third large project is the construction of the Copenhagen Metro. The construction of other major road and rail links are currently in the planning stages (The TransEuropean Transport Networks, 2005; Infrastrukturkommisionen, 2008), for example, a link across the Fehmarn Belt between Denmark and Germany. From an injury prevention perspective these large construction projects represent a great public challenge and this challenge is the main topic of this paper.

\section{Aim of the study}

Other research has developed methods for planning and management of time and the economy at large construction projects (Flyvbjerg, 2007). In this paper methods for planning and management of the prevention of occupational injuries is developed and presented.

The main research question of this study is: how can injury prevention be improved at large construction projects?

The specific objectives are:

- The primary objective is to propose a model for planning and management of the prevention of occupational injuries. The model is targeted at large construction projects and aiming at reducing injuries on future projects. 
- The second objective is, with reference to the proposed model, to categorize and evaluate existing injury prevention measures implemented at large construction projects in Denmark during the last two decades to demonstrate that improvements are possible.

Injury is damage or harm to the structure or function of the body caused by acute exposure to a physical agent or force. Injury prevention is a component of safety and health, and its goal is to protect the workers in their employment from injury risks resulting from external factors adverse to health. Injury prevention is any activity to prevent or reduce the severity of bodily injuries. This takes place at primary, secondary and tertiary prevention levels (Kines et al, 2007). The effects of an injury can be eliminated or reduced either by preventing them occurring (primary prevention), by reducing the initial effects through quick and effective medical and social care (secondary prevention), as well as various return to work schemes (tertiary prevention). All three prevention levels are included in the proposed injury prevention model.

\section{Methodology}

The paper first discusses the need for enhanced efforts on injury prevention at large construction projects. Second, an injury prevention model which describes the mechanisms behind the prevention measures and takes into account the phased process of construction projects is proposed. The model may be applied not only in the Danish construction industry, but in any country with a modern approach to occupational safety and health. The proposed injury prevention model is used to evaluate the effect of the existing injury prevention measures. The effect of safety measures implemented during the last two decades at large construction projects in Denmark are evaluated and discussed in relation to the proposed injury prevention model. The character (international joint ventures) of the large construction projects in Denmark and common EU guidelines for occupational safety suggests that the conclusions and recommendations also apply to large construction projects in other EU countries.

Injury prevention is a multi-disciplinary area and may involve interaction among many cognate disciplines, including safety engineering, statistics, epidemiology, occupational medicine, ergonomics, toxicology, public health, public policy, sociology and psychology. The present study is primarily based on quantitative methods from safety engineering, statistics and epidemiology in combination with socio-cultural methods from the third age of safety (Hale and Hovden, 1998) involving both personal (attitude and behaviour) and contextual (physical and organizational environment, social norms and culture) injury prevention factors (Lund, 2004).

The increasing complexity of construction projects creates the need for engineers and other professionals trained in all phases of the project's life 
cycle. Construction engineering is a discipline that attempts to meet this new challenge. An example is the CDIO (conceive, design, implement and operate) syllabus developed at Massachusetts Institute of Technology (Crawley, 2002). The CDIO syllabus objective is to create rational, complete and universal goals for engineering education. A large construction project consists in general of all four project phases: conceive, design, construction and operate. Research and practice has shown that many injuries could be avoided if the occupational risks had been foreseen during conceive and design phases (Behm, 2005; Spangenberg et al, 2005a; Gambatese et al, 2007). This research provides an argument for including all project phases in an injury prevention model targeted at large construction projects.

\section{Injury Risk}

\section{Injury rates}

According to the European Union's statistical unit, Eurostat, approximately 1300 construction workers are killed each year in the EU (Eurostat's homepage). This amounts to 13 fatalities out of every 100000 employees, more than twice the average of other industries. The European Agency for Occupational Safety and Health (OSHA) estimates that poor occupational health and safety standards in construction cost the EU and its taxpayers more than 75 billion euro each year (OSHA's homepage). Accurate figures are hard to obtain due to unregistered employees and unregistered accidents. In Denmark, with an estimated construction labour force of 175000 employees, approximately 4500 injuries are reported annually (according to Danish law, all injuries, which result in at least one day's absence from work after the day of the injury, must be reported to the National Working Environment Authority in Denmark. The NWEA has estimated the underreporting of injuries to approximately 50 per cent). This corresponds to an average injury rate for construction workers in Denmark of approximately 35 injuries per million working hours taking into account the underreporting. The number of fatalities is 10 per year in average (2001-2006). The overall injury rate has been falling for some years, but the decline seems to have stopped and been replaced by a new upward tendency (The Danish Working Environment Authority, 2008).

The Danish part of the trans-European transport network has been under continuous development during the last two decades. The Danish construction industry has been involved in the completion of three large and complex bridge and tunnel traffic links, the first being the Great Belt Link (1988-1998). During the construction of the Great Belt Link, it became clear that the injury rate was almost twice the average injury rate for construction workers in Denmark. During this project alone, seven workers were killed (The Danish Working Environment Authority, 2003). Major challenges were the international 
character of the contract holders (the contractors were organized in joint ventures) and the fact that a client-led health and safety organization had not yet been introduced. As a result of the experience from the Great Belt Link, a client-led health and safety organization was implemented during construction of the subsequent part of the transportation network.

Experienced human resources were transferred to the construction of the Øresund Link (1992-2000) between Denmark and Sweden, where attempts to improve safety and health went much further. The call for tenders contained occupational safety and health as an integral part of the construction work. A special safety and health committee was established with the client as chairman and with the participation of relevant stakeholders including the Danish Working Environment Authority. At the beginning of the construction period the injury rates were high, whereupon the client-led safety and health organization successfully implemented various occupational safety and health measures as described in Chapter 4. The injury rate fell to 20 injuries per million working hours, which was approximately one-third compared to the Great Belt Link (The Danish Working Environment Authority, 2003). The number of fatal accidents was reduced but not eliminated, as three workers lost their lives.

The third large construction project is the Copenhagen Metro (an ongoing project which began in 1993), where experience from the earlier projects was utilized again. Significant injury preventive results were obtained, sometimes under very difficult working conditions. Part of the Metro system was built under an existing commuter train which was in operation during the tunnel boring. The injury rate of the Metro project was approximately 30 injuries per million working hours during the first two stages (1993-2003). There were no fatalities (The Danish Working Environment Authority, 2003).

The injury rates at the large construction projects in Denmark have decreased significantly during the last years. Behind the improvements had been concerted efforts among the different stakeholders. Major public or semi-public contracting clients, The Danish Working Environment Authority, labour inspection authorities, the occupational health services, the unions, consultancies, contractors and their association worked together to reduce injuries during construction work. Several injury prevention measures were introduced at the projects and the preventive lessons of the large construction projects are evaluated further in Chapter 4.

\section{Injury risk factors}

Injury prevention models have developed from focusing on technical causes to focusing on dynamic interactions between man, machine, environment, organization and society (Reason, 1990; Glendon and McKenna, 1995; Hale and Hovden, 1998). The first age of safety was concerned with the technical 
measures to guard machinery, prevent fire and explosions, and prevent structures from collapsing. It lasted until the $1950 \mathrm{~s}$. It was then realized that technical risk assessment and technical prevention measures alone could not prevent injuries from occurring. The dominance of the technical view of safety in risk analysis and prevention was broken and the study of human error and human recovery came on the agenda. The second age of safety was concerned with the interaction between man and machine: the socio-technical injury prevention concept. The $1980 \mathrm{~s}$ was characterized by an increasing dissatisfaction with the idea that health and safety could be captured simply by matching the individual to technology. This led to the third age of safety, concerned with the interaction between man, machine, environment, organization and society, and where management systems are the focus point of injury prevention methods and involvement of the employees has become a key issue together with norms and values of the society (Hale and Hovden, 1998). The safety management methods started in high risk enterprises, that is, nuclear power plants and the aviation industry, but have spread to other industries, including the construction industry. This concept is a holistically approach to injury prevention, where the enterprises are viewed as social and cultural systems.

Injury risk is a combination of likelihood and consequence, and injury prevention measures may have an effect on both parameters:

Injury risk + injury prevention measure $=>$ Reduced injury risk, i.e. reduced likelihood and/or reduced consequences

In socio-cultural injury prevention models both personal factors, like attitude and behaviour, and contextual factors, like structural and cultural factors and social norms, govern the outcome of injury risk exposure (Lund, 2004).

Attitude is a hypothetical construct that represents an individual's like or dislike for an item, that is, a person, a behaviour or an event. Attitudes are composed from various forms of judgments. Attitudes may develop on the ABC model (affect, behavioural change and cognition) (Olson and Zanna, 1993). The affective response is a physiological response that expresses an individual's preference for an entity. The behavioural intention is a verbal indication of the intention of an individual. The cognitive response is a cognitive evaluation of the entity to form an attitude. Most attitudes in individuals are a result of observational learning from their environment.

Behaviour refers to the actions or reactions of an individual, usually in relation to the environment. Behaviour may develop on the KAP model (knowledge, attitude, practice or behaviour) (Olson and Zanna, 1993). The assumption is that increased knowledge will modify attitudes with regard to, for example, injury prevention and as a consequence behaviour will change, and injuries may be avoided. Behaviour can be conscious or unconscious, overt or covert, and voluntary or involuntary. Human behaviour can be common, unusual, 
acceptable or unacceptable. Humans evaluate the acceptability of behaviour using social norms and regulate behaviour by means of social control.

The structural factors consist of the physical environment, that is, the physical conditions at the construction site, and the organizational environment, that is, the political and economic organization of the construction company and the construction industry (Lund, 2004).

The contextual factors include cultural factors and social norms. Culture generally refers to patterns of human activity and the symbolic structures that give such activities significance and importance. Recently, the United Educational, Scientific and Cultural Organization (Unesco, 2002) described culture as follows: '... culture should be regarded as the set of distinctive spiritual, material, intellectual and emotional features of society or a social group, and that it encompasses, in addition to art and literature, lifestyles, ways of living together, value systems, traditions and beliefs'. A social norm is an assessment by the collective, while attitude is an assessment of the individual. In sociology a social norm is a rule that is socially enforced. Social sanctioning is what distinguishes norms from other cultural dimensions or social constructions such as beliefs and values. Norms are thought to affect a wide variety of human behaviour. Social norms can also be viewed as statements that regulate behaviour and act as informal social controls. They are usually based on some degree of consensus and are enforced through social sanctions.

Lund and Aarø (2004) have carried out a comprehensive literature review of 166 safety intervention studies, 13 meta-analysis of 133 studies and three systematic reviews of 35 studies covering a total of 332 different studies. The interventions were divided into four main categories with regard to the type of prevention measures utilized: attitude, behaviour or structural modification measures, and one category where measures from two or three of the main categories were used in combination (orchestration). Based on the review they find that some of the hypothesized paths in the injury risk factor model seem to be weak, for example, the KAP model, whereas others seem to be strong, for example, modification of physical and organizational environment followed by behavioural change. They conclude that when various preventive measures are used in combination, that is, orchestration, and the measures succeed in influencing social norms and public opinion, they are probably more effective than safety intervention targeting individuals only.

In a recent Cochrane review about interventions for preventing injuries in the construction industry (Van der Molen et al, 2007; Lehtola et al, 2008) a systematic search of the literature was conducted on preventing occupational injuries among construction workers. The quality of the studies was assessed and the effectiveness of interventions was evaluated. The full texts of 55 potentially eligible articles were examined, of which 15 described studies of interventions for preventing fatal and/or non-fatal occupational injuries among workers at construction sites. Five studies, four from the United States (Derr 
et al, 2001; Suruda et al, 2002; Lipscomb et al, 2003; Wickizer et al, 2004) and one from Denmark about the Øresund Link safety campaign (Spangenberg et al, 2002) met the Cochrane inclusion criteria (the Cochrane homepage) and were included in the review. The review concludes that there is moderate evidence that regulation alone is not effective in preventing non-fatal and fatal injuries in the construction industry. There is limited evidence that a safety campaign and a drug-free workplace programme are effective in reducing non-fatal injuries in the construction industry. Additional strategies are needed.

The safety intervention reviews provide an argument for including both personal factors and contextual factors in a socio-cultural injury prevention model for large construction projects.

\section{An Injury Prevention Model for Large Construction Projects}

\section{The project phases and injury prevention}

Construction engineering is a phased process. A large construction project consists in general of four project phases: conceive, design, implement (construction) and operate - CDIO (Crawley, 2002). These main phases may be divided into sub-phases. In the conceive phase the owner produces a list of requirements for a project, giving an overall view of the project's goals. Owners of these large projects are usually government agencies, either at the national or local level. Construction procurement describes the merging of activities undertaken by the owner (client) to obtain a building or a construction. There are many different methods of construction procurement; however the three most common types of procurement are: traditional design-bid-build, design and build, and management contracting.

\section{Contracting methods}

In the design-bid-build contract, the project is completely designed by the owner and his consultancies, then bid on by contractors, and then completed. Under this system, once the design is completed by the design team, construction companies are asked to make a bid for the work, either based directly on the design, or on the basis of drawings and a bill of quantities provided by the owner and his consultancy. Following evaluation of bids, the owner will typically award a contract to the lowest responsible bidder. At the large construction projects, it is often not just one contractor, but a consortium of several contractors working together.

In the design and build approach (turn-key contract) the contractor is given a performance specification by the client, and must undertake the project from design to construction to produce a completed fully functional construction or 
building, while adhering to the performance specifications. The contractor's ability to influence the construction process is limited by this method.

In the management contracting arrangement the client plays an active role in the procurement system by entering into separate contracts with the design consultancy and individual trade contractors. This approach is often used to speed up the procurement processes, allow the client greater flexibility in design variation throughout the contract, keep the ability to appoint individual trade contractors, separate contractual responsibility on each individual contractor, and to provide greater client control.

All three contracting methods have been used at the recent Danish infrastructure projects. In all three methods only the owner/client takes part in all four project phases.

The contracting methods provide an argument for letting the client be responsible for establishing an overview of injury prevention measures to be implemented during all the project phases of a large construction project.

\section{The designers' role in construction site safety}

The safety and health obligations of the designer are determined by the Danish legislation (Executive order No. 574 of 21 June 2001 on duties of the designers). The main obligations are: not to prescribe a substance or material that could be dangerous; point out the specific risks and other special circumstances involved with the specific project; indicate if there are specific conditions of the surroundings of the construction site, which may pose a particular risk to the workers (for example, stray ships); indicate how individual work or work processes must be organized in relation to each other. Furthermore, the design team should, as part of project material, provide a description of the characteristics of the construction to the extent they are relevant to safety and health during maintenance or repair of the structures. The description should include a list of the specific conditions to be observed in relation to safety and health of such future work.

The role of the design professional has traditionally been to design a building, or structure such that it conforms to accepted engineering practices, building codes, and is safe for the public. The safety of construction workers is partly left up to the contractors. However, design professionals can influence construction safety by making better choices in the design and planning stages of a project. In 1991 the European Foundation for the Improvement of Living and Working Conditions concluded that about 60 per cent of fatal injuries in construction are the result of decisions made before work begins at the site (Behm, 2005). Recent research has confirmed that a large percentage of construction injuries could have been eliminated by making better choices in the design stages of a project (Hecker et al, 2005; Gambatese et al, 2007). The ability to influence safety diminishes as the schedule moves from concept toward 
construction (Szymberski, 1997). Thus addressing construction safety in the design and planning phase can have a substantial impact on reducing injuries.

The research concerning the key role of design professionals' in construction safety provides an argument for including the design phase in an injury prevention model targeted at large construction projects.

\section{The contractors' role in construction site safety}

Safety during the construction phase is primarily the responsibility of the client and contractors. The safety and health obligations of the designer are determined by the Danish legislation (Executive Order No. 575 of 21 June 2001 with subsequent amendments on the safety and health activities of enterprises). The executive order deals with: organization of the safety and health activities; duties and rights of the employer and the employees; tasks and functions; the Central Internal Safety Organisation Committee; agreements, exemptions and appeals, and penalty provisions.

The safety of workers is often compromised by competing forces such as interrelationships between trades, the position and power of the trade, the nature of the work and economic and time pressures to complete a job (Cairns et al, 2008). These provide challenges for the main contractor in maintaining an integrated and consistent level of safety for workers of both the main contractor and subcontractors.

\section{The clients' role in construction site safety}

The client has four main obligations according to the Danish safety and health legislation (Executive order No. 576 of 21 June 2001 with subsequent amendments on duties of the client): coordinate the safety work at the site; define the limits of each contractor's safety work in site areas with more than one contractor; prepare a plan concerning safety and health at the site; notify the working environment authority about the site. These four obligations apply for all contracting methods. It is not possible for the client to delegate these obligations to the consultancy or the contractor. Thus the client has a decisive role in construction site safety.

The new proactive role of the client in construction site safety provides an argument for letting the client be responsible for establishing an overview of injury prevention measures to be implemented during all the project phases of a large construction project.

\section{The phased socio-cultural injury prevention model}

In the previous chapters arguments have been provided for combining the engineering CDIO-phase model with the socio-cultural approach to injury prevention into an injury prevention model targeted at large construction 


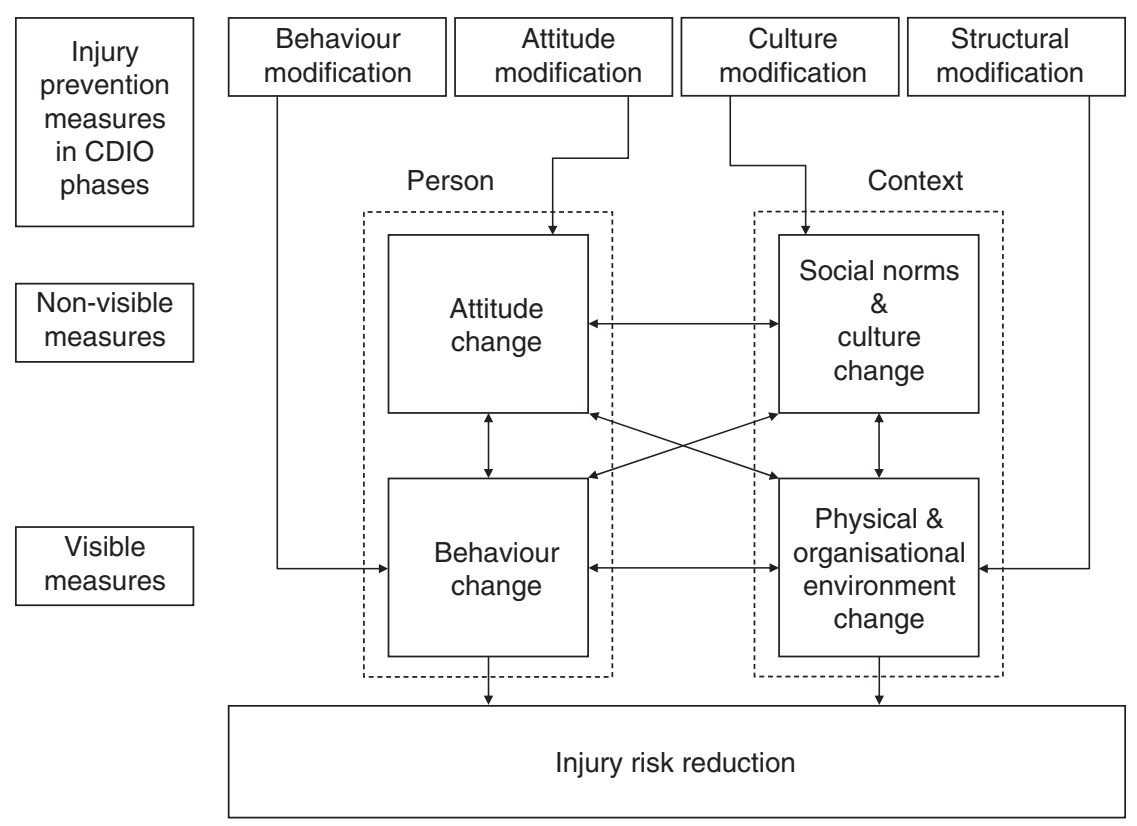

Figure 1: A CDIO-phased injury prevention model targeted large construction projects placing emphasis on both personal and contextual factors (adapted from Lund, 2004).

projects, see Figure 1 (adapted from Lund, 2004). Secondary and tertiary injury prevention has been included in the model.

The operation phase is also included in the injury prevention model. This is due to the fact that some of the safety measures, used for protection of the workers during the construction phase, are used during the operation phase for protection of the users of the traffic link, for example, barriers systems and surveillance systems (Vincentsen and Spangenberg, 1990). By preparing the interim solutions for the operation phase the most cost effective solutions may be obtained.

The second reason for including the operation phase in the model is the obligation of the client and the design team to design and built the structures such that safe work environment conditions can be obtained for the maintenance and repair workers during the operation phase (Boye-Møller et al, 1996).

The measures used for prevention of injuries at large construction projects should directly or indirectly influence the personal and/or contextual factors such that safety at the site is increased. The model may be applied not only in the Danish construction industry, but in all countries with a modern approach to occupational safety.

Attitudes are modified by increasing knowledge via persuasive and motivating messages in, for example, safety campaigns, campaign-mascots placed at 
the entrance to the site, leaflets explaining the purpose of the safety campaign, newsletters providing information on safety initiatives at the site, films showing good safety practices at the site, posters and notice boards placed in meeting rooms and direct mail to the employees.

Behaviour modification refers to measures for changing behaviour directly without trying to influence attitudes. Behaviour or working habits is changed, without assuming that attitudes have an intermediary function, by skills training (for example, toolbox meetings) and incentives. Incentives may be in the form of money (a safety bonus or a safety award), feedback or social recognition. Incentives alter the exchange relationship between employer and employees, and increase task performance. Money fosters effort, feedback clarifies tasks and social recognition predicts outcomes. All three in combination have the greatest effects (Stajkovic and Luthans, 2003).

The structural injury risk factors are associated with the physical and the organizational environment. The physical risk factors are determined by the physical conditions at the construction site: the site constraints, the site layout/ space, camps for accommodation of workers, the weather conditions at the site (hot, cold, wet, ice, flood), machines and equipment, materials, scaffolding and ladders, protection against falling from heights, lightning and electricity, and housekeeping, and so on. The physical injury prevention measures include safety walk rounds at the site, where a number of physical safety aspects are inspected and evaluated, typically ones a week. The physical environment may include objects (stray ships or cars) from outside the construction site penetrating into the work zone. These external risks are eliminated or reduced by surveillance systems (for example, vessel traffic service systems) and barriers systems (for example, guard ships and crash fence). The organizational environment is determined by the contracting method chosen by the client, the contractors' organization at the construction site, work scheduling, and at macro level the political and economic organization of the construction companies and the construction industry. Organizational risk factors are changed through legislation, regulation, organization and economy. The organizational injury prevention measures include safety management systems and safety audits (Hale and Hovden, 1998).

Culture has been called 'the way of life for an entire society'. As such, it includes codes of manners, dress, language, religion, rituals, norms of behaviour such as law and morality, beliefs and values. Social norms can be viewed as statements that regulate behaviour and are enforced through social sanctions. Social sanctioning is what distinguishes norms from other cultural dimensions like beliefs and values.

Two concepts, safety culture and safety climate, have been introduced in injury prevention research. Dov Zohar (2000) defines safety climate as the employees' shared perceptions of management's commitment and performance with regards to safety policies, procedures and practices. Whereas safety climate 
is a psychological construct referring to shared perceptions, safety culture is generally taken to refer to the basic values and beliefs regarding safety in the organization, and is considered to be a more persistent construct that is harder to influence directly (Mearns and Flin, 1999; Guldenmund, 2000). However, relationships and differences between the two concepts are to some extent unclear. While they can be differentiated to a certain extent in theory, the means by which they have been operationalized often makes it difficult to distinguish the two concepts in practice. The distinction has been grounded in methodological issues, where climate usually is assessed through quantitative measures, that is, questionnaires, while culture is assessed via qualitative interviews and anthropological methods (Mearns and Flin, 1999; Guldenmund, 2000). Although consensus on definition and measurement issues is still lacking, there is agreement about the main dimensions of safety climate. Recent safety research clearly shows the importance of managerial factors such as management commitment to injury prevention (Flin, 2003). Worker involvement in safety planning has also been identified as an important factor in safety climate (Dedobbeleer and Beland, 1991). In the proposed injury prevention model the broader term, culture, has been chosen in order not to eliminate possible safety measures. It may be a challenge to identify cultural dimensions that have an impact on safety practice (Dejoy, 2005). However, changing relevant aspects of the culture may, at least in the long run, prove to be among the most effective injury preventive measures (Lund, 2004).

\section{Injury Preventive Measures for Large Construction Projects}

In a recent Cochrane review, dealing with interventions for preventing injuries in the construction industry, a systematic search of the literature was conducted on preventing occupational injuries among construction workers. It was concluded that the majority of technical, human factors and organizational interventions which are recommended by standard texts of safety, consultants and safety courses have not been adequately evaluated, and that there is an urgent need to address this gap in the evidence base (Van der Molen et al, 2007; Lehtola et al, 2008).

In Table 1 the injury prevention measures, implemented during the last two decades at large Danish construction projects, are shown. The majority was implemented at the initiative of the client. Some of the injury prevention measures originate from the work environment legislation, while others go beyond the law. The injury prevention measures are discussed and categorized in accordance with the proposed construction injury prevention model. Type of injury prevention measure, injury prevention level and project phase appear from the model. Furthermore, if relevant injury data were available, the effect of the injury prevention measure has been evaluated. The main results of the evaluations are presented below. 


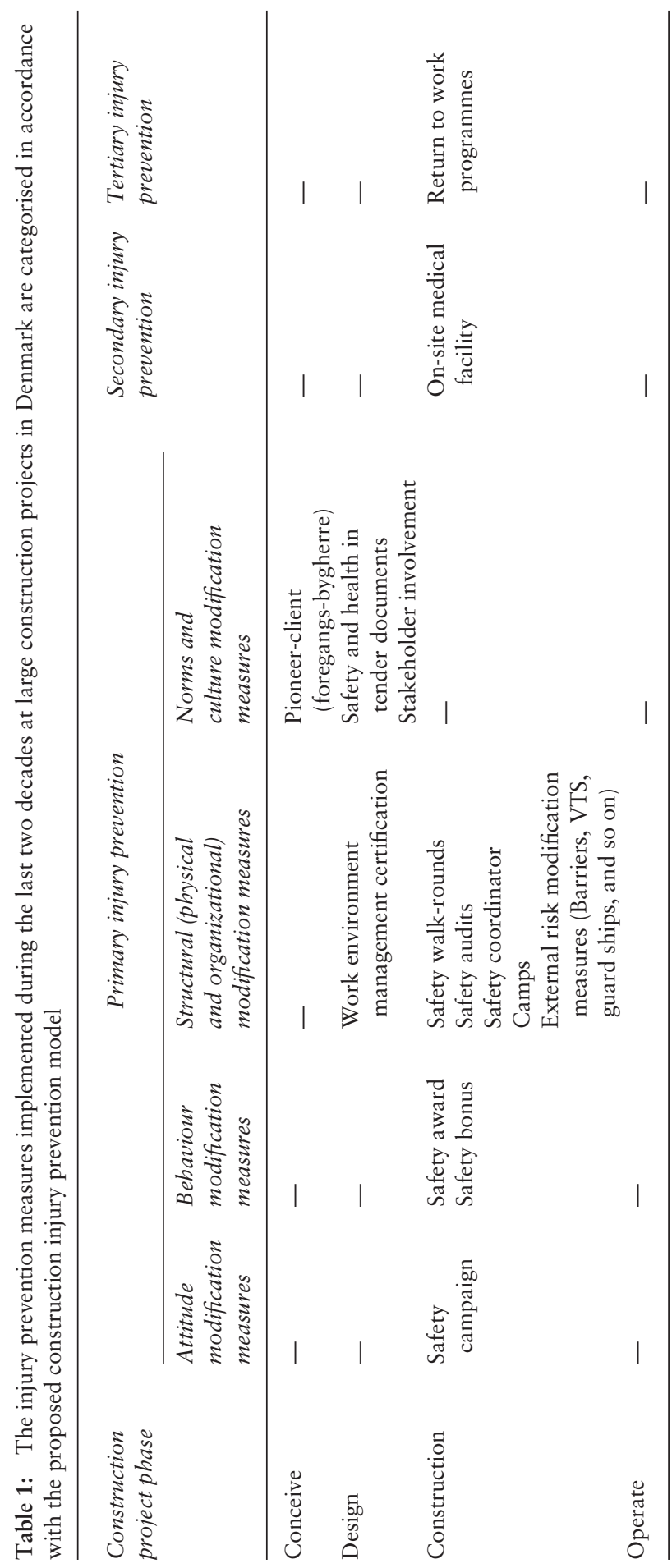


In 1996 the European Agency for Safety and Health at Work was founded and member states of the European Union have all transposed into their national legislation a series of directives that establish minimum standards on occupational safety and health (the European Agency for Safety and Health at Work's homepage). These directives follow a similar structure requiring the employer to assess the workplace risks and put in place preventive measures based on a hierarchy of control. This hierarchy starts with elimination of the hazard and ends with personal protective equipment. In the European Union, member states have enforcing authorities to ensure that the basic legal requirements relating to occupational safety and health are met. The organization of the large construction projects in Denmark (international joint ventures) and the common EU guidelines for occupational safety suggests that the following conclusions also apply to large construction projects in other EU countries.

As shown in Table 1 most of the safety initiatives belong to the category structural (physical and organizational) modification measures. Other safety initiatives aimed at attitude change and behaviour change. Finally a few initiatives aimed at modification of norms. It appears from the model that there is a potential for increasing the orchestration of injury prevention measures on future projects.

The majority of the injury prevention measures were implemented during the construction phase. The Øresund Link safety campaign was primarily based on the KAP-model (Spangenberg et al, 2002). The effect of the campaign was a 25 per cent reduction of injuries. This effect became only just statistically significant when heterogeneity of type of work before and after the campaign was taken into account. The modest effect of the safety campaign indicates that safety campaigns only result in limited behaviour change unless combined with an effective behavioural safety intervention (Zohar and Erev, 2007). Safety bonuses were used to promote safe behaviour. Incentives like safety bonus and safety awards alter the exchange relationship between employer and employees, and increase task performance (Stajkovic and Luthans, 2003). However, there is a risk that money as incentive may lead to underreporting of injuries (Dyreborg et al, 2004).

The safety walk-rounds aimed at reducing injuries by making the physical conditions at the site safer. Feedback concerning safety performance was used as incentive to change behaviour. Effect evaluations of walk-rounds indicate that safety walk-rounds both predict and prevent injuries (Mikkelsen et al, 2008). The average time period to the next injury is substantially increased after a safety walk-round. Safety audits aimed at increasing safety and reducing injuries by checking for compliance between safety practices of the employees and the safety management system. Feedback concerning non-compliance was used as incentive to change behaviour. Nielsen et al (2008) found that differences in audit compliance between plants were reflected in corresponding differences in injury rates. The client introduced a safety coordinator at the 
site. This is an organizational modification measure aiming at increasing safety at the site by actively coordinating the various contractors' safety work at the joint meetings. Furthermore, the client-appointed safety coordinator carried out safety walk-rounds and participated in safety audits. Introduction of the safety coordinator was a success and the function became part of the Danish occupational safety and health legislation in 2001. On the basis of the results of a recent study, comparing safety performance among main contractors and subcontractors (Spangenberg et al, forthcoming) and previous work by Zohar and Luria (2003), it has been proposed, in relation to the forthcoming revision of the client regulations, that the tasks of the safety coordinator should be expanded to include a coaching role. The safety coordinator should provide feedback to site management and work supervisors regarding proactive safety goals, as a supplement to injury rates.

Many large-scale construction projects take place in less populated areas, where thousands of workers are recruited for a limited time and therefore usually have their homes far away from the construction sites. Temporary building camps are usually established in connection with such construction projects. Tüchsen and Hannerz (2004) found that high injury rates at large construction sites may be reduced, if commuting is replaced by living in camps. The relative risk for all injuries for camp vs non-camp workers was 0.84 (95 per cent CI 0.69-1.00). Thus the study indicates that camps may be seen as a structural injury prevention measure. According to Danish legislation, designers of construction projects have an obligation to state if there are special conditions in the vicinity of a construction site which may constitute serious risks for the construction workers. These external risks are examples of physical risks where prevention of initiating events is no option for the contractor. Instead the contractor must protect the employees inside the work zone. Protection involves primarily the use of physical safety measures like barriers and surveillance systems (Pratt et al, 2001; Hollnagel, 2007). It is argued that while barriers are necessary, they basically represent a reactive approach which is insufficient by itself to guarantee safety. Furthermore, the barrier systems are typically very expensive.

The Øresund Link, as well as other complex and/or remote construction projects, built within the last decade, has incorporated various forms of on-site medical facilities (Spangenberg et al, 2005b). These facilities are examples of secondary injury prevention. The primary objective of the medical facilities was to provide immediate medical assistance and good health care to workers subjected to injury incidents at work, in order to reduce the consequences of the injuries. The secondary objective was to reduce the amount of lost working time. The study showed a statistically significant on-site treatment (and resume work) rate ratio of 3.3 (95 per cent CI 2.3-4.3) between the nurse-based (76 per cent returned to work after treatment) and the first-aid-based (23 per cent returned) medical facility. The study shows a need for on-site medical 
facilities, particularly at remote construction sites, and that it is essential that the medical personnel have both the qualifications and authorization to effectively treat site-specific workplace injuries in order to obtain high on-site treatment rates.

Only a few injury prevention measures have been implemented during conceive and design phases so far. Most of these measures also covered the construction phase. In the Pioneer-client campaign it is realized that the client plays a crucial role in the work environment at the centre of the construction projects from idea to finished structure and the campaign is an example of how attitude and behaviour change regarding safety and health may influence the norms of the construction industry (Branchearbejdsmiljørådet Bygge and Anlæg, 2007). Tender documents consist of legal conditions and technical specifications. The documents constitute the basis of the contractors' bid. In recent large construction projects, legal conditions and technical specifications concerning the work environment have been incorporated in the tender documents (A/S Øresundsforbindelsen, 1994). The contractors' response to the work environment requirements in the tender documents was part of the client's evaluation of the contractors' bid. This is probably one of the most important safety measures implemented by the client. This is an example of how clients of large construction projects via incentives (achieve contract) may influence safety and health norms and standards of several contractors. Certification of quality, environment and the working environment was seen as a means to professionalize the management of the project. Enterprises that obtain a safety and health safety certificate meet the statutory safety and health requirements. The Danish Working Environment Authority will therefore only in special cases supervise enterprises with a safety and health certificate. Certification is an example of an organizational modification measure.

Injury prevention has increasingly become a topic of interest for stakeholders. The clients on the most recent large construction projects established safety committees with the participation of relevant stakeholders (Vincentsen and Spangenberg, 1990; Boye-Møller et al, 1995). This development may be seen as part of the more comprehensive development in corporate social responsibility (CSR), where enterprises are expected to take responsibility for the prevention and resolution of social problems. In a recent study by Dyreborg et al (2006), it is investigated how this development has influenced clients' responsibilities in the construction industry, both in relation to safety at work and in the strategic management of stakeholder interests. The study showed that the strategy for management of the institutional environment has changed from being primarily defensive and reactive to being proactive. Stakeholder interest gave an impetus to the establishment of client responsibility at larger public construction projects, which had a positive impact on safety management on the construction sites. This is an example of how changed norms in the society may change safety management of construction companies. 
The above results are supported by a comprehensive review of safety intervention studies (Lund and Aarø, 2004). The study indicates that some of the hypothesized paths in the injury prevention model seem to be weak, for example, the KAP model, while others seem to be strong, for example, modification of physical and organizational environment followed by behavioural change. They conclude that when various preventive measures are used in combination, that is, orchestration, and the measures succeed in influencing social norms and public opinion, they are probably more effective than safety intervention targeting individuals only.

\section{Conclusions}

The construction industry continues to be one of the most hazardous industries in Europe. The incidence rate for non-fatal and fatal injuries exceeds that of many other industries, and there is a great need for new effective methods for prevention of injuries.

\section{An injury prevention model for large construction projects}

Safety intervention reviews (Lund and Aarø, 2004; Van der Molen et al, 2007; Lehtola et al, 2008) indicates that when various preventive measures are used in combination, that is, orchestration, and the measures succeed in influencing social norms and public opinion, they are more effective than safety intervention targeting individuals only. The reviews provide an argument for including both personal factors (attitude, behaviour) and contextual factors (physical, organizational, cultural) in a socio-cultural injury prevention model for large construction projects.

Recent research has showed that a large percentage of construction injuries could have been eliminated or the risk reduced by making better choices in the design phase of a project (Behm, 2005; Hecker et al, 2005; Gambatese et al, 2007). The research concerning the key role of design professionals in construction safety provides an argument for including conceive and design phases in an injury prevention model targeted at large construction projects. The operation phase is also included in the injury prevention model. Some of the safety measures, used for protection of the workers during the construction phase, are reused during the operation phase for protection of the users of the traffic link, for example, barriers systems and surveillance systems. By preparing the interim solutions for the operation phase the most cost effective solutions may be obtained. The second reason for including the operation phase in the model is the obligation of the client and the design team to design and built the structures such that safe work environment conditions can be obtained for the maintenance and repair workers during the operation phase. 
The injury prevention model targeted at large construction projects is obtained by combining the engineering CDIO-phase model (conceive, design, implement or construction, operate) with the socio-cultural approach to injury prevention. Secondary (reducing the initial effects through quick and effective medical care) and tertiary (various return to work schemes) injury prevention has been included in the model. The model may be applied in countries with a modern approach to occupational safety.

The strength of the proposed injury prevention model is that it relates to the mechanism behind the specific injury prevention measure, and provides an overview of the types of injury prevention measures already implemented, and in which project phase they apply. The model thus provides the opportunity to carry out the recommended orchestrating of injury prevention measures.

The contracting methods in construction, which implies that only the client takes part in all four project phases, and the new proactive role of the client provide an argument for letting the client be responsible for establishing the proposed injury prevention model, hereby creating a total overview of injury prevention measures to be implemented during all the project phases of a large construction project. Implementation of the proposed injury prevention model may be voluntary or statutory. A study by Smith and Tombs (1995) indicates a number of regulatory developments which are distinct from any shift towards greater self-regulation, but which would result in more effective crisis and disaster prevention in the UK chemicals industries and other sectors.

\section{Injury prevention measures for large construction projects}

The study shows that injury rates at the large construction projects in Denmark have decreased significantly during the last 20 years. Behind the improvements had been concerted efforts among the different stakeholders. Major public or semi-public clients, The Danish Working Environment Authority, labour inspection authorities, the occupational health services, the unions, consultancies, contractors and their association worked together to reduce injuries during construction work. Several injury prevention measures were introduced at the projects and the preventive lessons of these measures have been evaluated in this study. The evaluations show that further reduction of injury rates is possible.

Injury prevention measures, implemented at recent large Danish construction projects, have been categorized in accordance with the proposed injury prevention model. The mechanism behind the injury prevention measure, injury prevention level and project phase appear from the model. Most of the safety initiatives belonged to the category structural (physical and organizational) modification measures (for example, safety walk-rounds). Effect evaluations of safety walk-rounds indicated that they both predict and prevent injuries. The average time period to the next injury was substantially increased 
after a safety walk-round. Other safety initiatives aimed at attitude change (campaigns) and behaviour change (incentives). The safety campaigns were primarily based on the KAP-model and had a modest effect. Incentives like safety bonuses alter the exchange relationship between employer and employees, and increase task performance. However, there is a risk that money as incentive may lead to underreporting of injuries. Only few measures aimed at modification of norms and culture (for example, stakeholder involvement). Injury prevention has increasingly become a topic of interest for stakeholders. This development may be seen as part of the more comprehensive development in CSR, where enterprises are expected to take responsibility for the prevention and resolution of social problems. The study showed that the strategy for management of the institutional environment has changed from being primarily defensive and reactive to being proactive. Stakeholder interest gave an impetus to the establishment of client responsibility at larger public construction projects, which had a positive impact on safety management on the construction sites.

The study indicates that injury prevention may be improved at future projects by implementing more measures influencing norms and culture at the construction site and thus increase the diversity of injury prevention measures. Many injury incidents originate from the design phase. Future safety research should focus more on developing injury prevention measures for this phase.

The character (international joint ventures) of the large construction projects in Denmark and common EU guidelines for occupational safety suggests that the conclusions and recommendations also apply to large construction projects in other EU countries.

\section{Recommendations and Practical Implications}

The recommendations of the study may be seen as input to the Danish occupational injury prevention strategy for future extensions of the transportation network, for example, the Fehmern Belt link between Denmark and Germany, and other large construction projects.

Based partly on the contracting methods in construction, which implies that only the client takes part in the project from concept to final structure, and partly on the new proactive safety role of the client defined by recent legislation it is recommended to let the client be responsible for establishing the proposed injury prevention model, and hereby create an overview of injury prevention measures to be implemented during all the project phases of a large construction project.

It is recommended to supplement personal and structural injury prevention measures with measures influencing social norms and safety culture, and to increase the orchestration of injury prevention measures on future projects.

Many injury incidents originate from the design phase. It is recommended that future safety research and practice focuses more on injury prevention measures for the design phase. 


\section{Acknowledgements}

I wish to thank my colleagues at the National Research Centre for the Working Environment in Denmark. Thank you to Elsa Bach, Kim Lyngby Mikkelsen, Johnny Dyreborg, Pete Kines, Bryan Cleal, Hitomi Shibuya, Harald Hannerz and Finn Tüchsen. Thank you to the client companies, A/S Storebæltsforbindelsen, A/S Øresundsforbindelsen and the Copenhagen Metro, for the permission to use the injury data in research. Thank you to the funds which have supported the study, especially the national working environment research fund in Denmark.

\section{References}

A/S Øresundsforbindelsen. (1994) (in Danish) Fællesbetingelser (Legal conditions). A/S Øresundsforbindelsen, København, 3. udgave, juni 1994.

Behm, M. (2005) Linking construction fatalities to the design for construction safety concept. Safety Science 43(8): 589-611.

Boye-Møller, K., Spangenberg, S. and Andersen, O.V. (1996) Operation and maintenance of the Danish landworks of the fixed link across Øresund, Proceedings of the Tunnel Management, Operation and Maintenance; 3-4 June, Hong Kong.

Boye-Møller, K., Thomsen, J.V., Spangenberg, S. and Gudum, P. (1995) Safety concept for the Danish landworks of the Øresund fixed link. Safety in road and rail tunnels, Proceedings of the Second International Conference; April, Granada, Spain, pp. 593-600.

Branchearbejdsmiljørådet Bygge and Anlæg. (2007) (in Danish). Når bygherren går foran (When the client goes ahead)Guidelines, Branchearbejdsmiljørådet Bygge \& Anlæg. Maj 2007 ISBN 978-87-7952-098-1.

Brenner, H. and Ahern, W. (2000) Sickness absence and early retirement on health grounds in the construction industry in Ireland. Occupational and Environmental Medicine 57(9): 615-620.

Cairns, J., Adie, W. and Osman, L. (2008) Measurement of risk perception in the offshore oil and gas industry. Risk Management 10: 205-217.

Crawley, E.F. (2002) Creating the CDIO syllabus, a universal template for engineering education, 32nd ASEE/IEEE Frontiers in Education Conference; 6-9 November, Boston, MA.

Dedobbeleer, N. and Beland, F. (1991) A safety climate measure for construction sites. Journal of Safety Research 22(2): 97-103.

DeJoy, D.M. (2005) Behaviour change versus culture change: Divergent approaches to managing workplace safety. Safety Science 43: 105-129.

Derr, J., Forst, L., Chen, H.Y. and Conroy, L. (2001) Fatal falls in the US construction industry, 1990 to 1999. Journal of Occupational and Environmental Medicine 2001 43(10): 853-860.

Dong, W., Vaughan, P., Sullivan, K. and Fletcher, T. (1995) Mortality study of construction workers in the UK. International Journal of Epidemiology 24(4): 750-757.

Dyreborg, J., Spangenberg, S. and Cleal, B. (2006) Stakeholder interests as a driving force in improved client responsibility for safety at large construction sites, 3rd International Conference Working on Safety. Abstract Book; 12-15 September, 2006; Zeewolde, the Netherlands. 
Dyreborg, J., Cleal, B., Spangenberg, S. and Nielsen, K. (2004) Organisational Responses to the Use of Performance Measurements in Occupational Safety - Workmanship or gamesmanship? 20th EGOS Colloquium; 1-3 July, Ljubljana University, Slovenia.

Eurostat's homepage http://epp.eurostat.ec.europa.eu.

Flin, R. (2003) Danger - men at work: Management influence on safety. Human Factors \& Ergonomics in Manufacturing 13(4): 261-268.

Flyvbjerg, B. (2007) Megaproject policy and planning: Problems, causes, cures. Doctoral dissertation, Department of Development and Planning, Aalborg University, Denmark.

Gambatese, J.A., Behm, M. and Rajendran, S. (2007) Design's role in construction accident causality and prevention: Perspectives from an expert panel. Safety Science 46(2008): 675-691.

Glendon, A.I. and McKenna, E.F. (1995) Human Safety and Risk Management. London: Chapman \& Hall.

Guldenmund, F.W. (2000) The nature of safety culture: A review of theory and research. Safety Science 34(1-3): 215-257.

Hale, A.R. and Hovden, J. (1998) Management and culture: The third age of safety. A review of approaches to organizational aspects of safety, health and environment. In: A.M. Feyer and A. Williamson (eds.) Occupational Injury: Risk, Prevention and Intervention. London: Taylor \& Francis, pp. 129-165.

Hannerz, H., Spangenberg, S., Tüchsen, F. and Albertsen, K. (2005) Disability retirement among former employees at the construction of the great belt link. Public Health 119: 301-304.

Hecker, S., Gambatese, J. and Weinstein, M. (2005) Designing for worker safety. Professional Safety, 50(9): 32-44.

Hollnagel, E. (2007) Risk+barriers=safety? Safety Science 46(2): 221-229.

Infrastrukturkommisionen. (2008) (in Danish) Danmarks transportinfrastruktur 2030. Betænkning 1493 fra Infrastrukturkommissionen (ISBN: 978-87-91511-83-7), januar 2008.

Kines, P., Spangenberg, S. and Dyreborg, J. 2007 Prioritizing occupational injury prevention in the construction industry: injury severity or absence? Journal of Safety Research 38: 53-58.

Lehtola, M.M. et al (2008) The effectiveness of interventions for preventing injuries in the construction industry: A systematic review. American Journal of Preventive Medicine 35(1): 77-85.

Lipscomb, H.J., Li, L. and Dement, J. (2003) Work-related falls among union carpenters in Washington state before and after the vertical fall arrest standard. American Journal of Industrial Medicine 44: 157-165.

Lund., J. (2004) Epidemiology, registration and prevention of accidental injuries. Doctor's dissertation, University of Oslo.

Lund, J. and Aarø, L.E. (2004) Accident prevention. Presentation of a model placing emphasis on human, structural and cultural factors. Safety Science 42: 271-324.

Mearns, K.J. and Flin, R. (1999) Assessing the state of organizational safety - Culture or climate? Current Psychology: Developmental, Learning, Personality, Social 18(1): 5-17.

Mikkelsen, K.L., Spangenberg, S. and Kines, P. (forthcoming) The effect of safety walkrounds in predicting injury and reducing injury risk in the construction industry. Journal of Industrial Medicine, (in press).

Nielsen, K., Rasmussen, K., Glasscock, D. and Spangenberg, S. (2008) Changes in safety climate and accidents at 2 identical manufacturing plants. Safety Science 46: 440-449. 
Olson, J.M. and Zanna, M.P. (1993) Attitudes and attitude change. Annual Review of Psychology 44: 117-154.

Pratt, S.G., Fosbroke, D.F. and Marsh, S.M. (2001) Building safer highway work zones: measures to prevent worker injuries from vehicles and equipment. DHHS/NIOSH Pub. No.2001 2128.

Reason, J.T. (1990) Human Error. Cambridge: Cambridge University Press.

Smith, D. and Tombs, S. (1995) Beyond self-regulation: Towards a critique of selfregulation as a control strategy for hazardous activities. Journal of Management Studies 32(5): 619-636.

Spangenberg, S., Hannerz, H. and Tüchsen, F. (2005a) Hospitalized injuries among bridge and tunnel construction workers. Construction Management and Economics 23(3): 237-240.

Spangenberg, S., Mikkelsen, K.L., Kines, P. and Dyreborg, J. (2005b) The efficiency in reducing lost-time injuries of a nurse based and a first aid based on-site medical facility: The construction of the Øresund link between Sweden and Denmark. Scandinavian Journal of Work Environment and Health 31(2): 104-109.

Spangenberg, S., Mikkelsen, K.L., Kines, P., Dyreborg, J. and Baarts, C. (2002) The construction of the Oresund link between Denmark and Sweden: The effect of a multifaceted safety campaign. Safety Science 40: 457-465.

Spangenberg, S., Cleal, B., Kines, P., Kristensen, E.L., Mikkelsen, K.L. and Dyreborg, J. (forthcoming) Safety communication and safety performance among main contractors and subcontractors in construction.

Stajkovic, A.D. and Luthans, F. (2003) Behavioral management and task performance in organizations: Conceptual background, meta-analysis, and test of alternative models. Personnel Psychology 56: 155-194.

Suruda, A., Whitaker, B., Bloswick, D., Philips, P. and Sesek, R. (2002) Impact of the OSHA trench and excavation standard on fatal injury in the construction industry. Journal of Occupational and Environmental Medicine 44(10): 902-905.

Szymberski (1997) Construction project safety planning. TAPPI Journal 80(11): 69-74.

The Cochrane homepage http://wwwcochrane.org/reviews/revstruc.htm.

The Danish Working Environment Authority. (2003) (in Danish) Arbejdstilsynet Arbejdsmiljø, helbred og camps. At-rapport nr. 2-2003.

The Danish Working Environment Authority. (2008) (in Danish) Arbejdstilsynet Analyse i stigning i anmeldte arbejdsulykker 2003-2006, januar 2008 (www.at.dk).

The European Agency for Safety and Health at Work's homepage http://osha.europa.eu/.

The Trans-European Transport Networks' homepage http://ec.europa.eu/ten/transport/.

The Trans-European Transport Networks, TEN-T priority axes and projects. (2005) Directorate-General for Energy and Transport, European Commission.

Tüchsen, F. and Hannerz, H. (2004) Building camps and work related injuries. Occupational and Environmental Medicine 61(4): 370-371.

Tüchsen, F., Hannerz, H. and Spangenberg, S. (2005) Mortality and morbidity among bridge and tunnel construction workers who worked long hours and long days constructing the great belt link. Scandinavian Journal of Work Environment and Health 31(2): 22-26.

UNESCO. (2002) Universal declaration on cultural diversity. issued on International Mother Language Day, 21 February 2002.

Van der Molen, H.F. et al (2007) Interventions for preventing injuries in the construction industry. Cochrane Database of Systematic Reviews 2007, Issue. Art. No. CD006251. DOI:101002/14651858. CD006251.pub2. 
Vincentsen, L.J. and Spangenberg, S. (1990) Safety management system for the Great Belt link, (invited paper), Proceedings of the 2nd Symposium on Strait Crossings; June, Trondheim, Norway, pp. 527-531.

Wickizer, T.M., Kopjar, B., Franklin, G. and Joesch, J. (2004) Do drug-free work-place programs prevent occupational injuries? Evidence from Washington state. Health Services Research 39(1): 91-110.

Zohar, D. (2000) A group-level model of safety climate: Testing the effect of group climate on microaccidents in manufacturing jobs. Journal of Applied Psychology 85(4): 587-596.

Zohar, D. and Erev, I. (2007) On the difficulty of promoting workers' safety: Overcoming the underweighting of routine risks. International Journal of Risk Assessment and Management 7(2): 122-136.

Zohar, D. and Luria, G. (2003) The use of supervisory practices as leverage to improve safety behaviour: A cross level intervention model. Journal of Safety Research 34: 567-577. 